\title{
Modulation of cortisol responses to the DEX/CRH test by polymorphisms of the interleukin-1 beta gene in healthy adults
}

Daimei Sasayama ${ }^{1,2^{*}}$, Hiroaki Hori ${ }^{1,4}$, Yoshimi lijima ${ }^{1,3}$, Toshiya Teraishi ${ }^{1}$, Kotaro Hattori ${ }^{1}$, Miho Ota ${ }^{1}$, Takashi Fujii ${ }^{1}$, Teruhiko Higuchi ${ }^{1}$, Naoji Amano ${ }^{2}$ and Hiroshi Kunugi ${ }^{1,4}$

\begin{abstract}
Background: Recently, hypothalamus-pituitary-adrenal (HPA) axis function assessed with the combined dexamethasone (DEX)/corticotropin releasing hormone (CRH) test has been shown to be associated with response to antidepressant treatment. A polymorphism (rs16944) in the interleukin-1beta (IL-1 $\beta$ ) gene has also been reported to be associated with the medication response in depression. These findings prompted us to examine the possible association between $I L-1 \beta$ gene polymorphisms and HPA axis function assessed with the DEX/CRH test.

Methods: DEX/CRH test was performed in 179 healthy volunteers (45 males: mean age $40.5 \pm 15.8$ years; 134 females: mean age $47.1 \pm 13.2$ years). Five tagging single nucleotide polymorphisms (SNPs) of IL-1 $\beta$ gene (rs2853550, rs1143634, rs1143633, rs1143630, rs16944) were selected at an $r^{2}$ threshold of 0.80 with a minor allele frequency $>0.1$. Genotyping was performed by the TaqMan allelic discrimination assay. A two-way factorial analysis of variance (ANOVA) was performed with the DEX/CRH test results as the dependent variable and genotype and gender as independent variables. To account for multiple testing, $P$ values $<0.01$ were considered statistically significant for associations between the genotypes and the cortisol levels.

Results: The cortisol levels after DEX administration (DST-Cortisol) showed significant associations with the genotypes of rs16944 ( $P=0.00049)$ and rs1143633 ( $P=0.0060$ ), with no significant gender effect or genotype $\times$ gender interaction. On the other hand, cortisol levels after CRH administration (DEX/CRH-Cortisol) were affected by gender but were not significantly influenced by the genotype of the examined SNPs, with no significant genotype $\times$ gender interaction.

Conclusions: Our results suggest that genetic variations in the $I L-1 \beta$ gene contribute to the HPA axis alteration assessed by DST-Cortisol in healthy subjects. On the other hand, no significant associations of the $I L-1 \beta$ gene polymorphisms with the DEX/CRH-Cortisol were observed. Confirmation of our findings in futures studies may add new insight into the communication between the immune system and the HPA axis.
\end{abstract}

\section{Background}

Recent studies have provided several lines of evidence implicating the pro-inflammatory cytokine interleukin1beta (IL-1 $\beta$ ) in the etiology and pathophysiology of depression. Studies investigating peripheral levels of IL$1 \beta$ have reported elevated concentrations of IL- $1 \beta$ in patients with major depression [1-3] and dysthymia

\footnotetext{
* Correspondence: sasayama@shinshu-u.ac.jp

'Department of Mental Disorder Research, National Institute of Neuroscience, National Center of Neurology and Psychiatry, Kodaira, Tokyo, 187-8502, Japan

Full list of author information is available at the end of the article
}

$[4,5]$. In experimental animals, exogenous administrations of IL-1 $\beta$ have produced depressive-like symptoms, which were attenuated by treatment with antidepressants [6,7]. Furthermore, administration of the IL-1 receptor antagonist has ameliorated the stress-like effects in cellular and behavioral models [8,9], making it a possible candidate for therapeutic targets.

A few studies have examined genetic polymorphisms of the $I L-1 \beta$ gene for association with depression. Although no significant allelic or genotypic differences have been found between patients with depression and

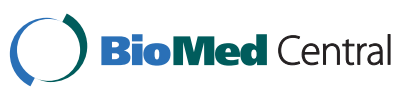


healthy controls [10-12], three studies have consistently shown that the $\mathrm{G}$ allele of rs 16944 in the $I L-1 \beta$ gene is associated with poor response to antidepressant treatment $[10,13,14]$. This evidence suggests that genetic regulation of inflammatory processes mediated by IL- $1 \beta$ is involved in the pathophysiology of depression and resistance to antidepressant treatment.

Alterations in the hypothalamic-pituitary-adrenal (HPA) axis have been well-documented in depression and related psychopathological conditions (reviewed by $[15,16])$. We have also reported heightened HPA axis in major depression and its normalization after treatment as assessed with the combined dexamethasone (DEX)/ corticotropin releasing hormone $(\mathrm{CRH})$ test $[17,18]$. The relationship between alteration of the HPA axis activation and immune alterations in depression has been described in several studies [19-21]. The increased expression of pro-inflammatory cytokines is thought to lead to the progression of the immune response and activation of the HPA axis [22-24]. In particular, IL-1 $\beta$ is considered to play an important role in the HPA axis alteration. A significant positive correlation between mitogen-induced IL-1 $\beta$ production and post-DEX cortisol values have been reported, suggesting that IL-1 $\beta$ hypersecretion may contribute to HPA axis hyperactivity [25]. Animal studies have further demonstrated that the release of CRH stimulated by IL-1 is involved in the HPA activation [26-28].

Intriguingly, a number of studies have shown that the DEX/CRH test may be a predictor for response to antidepressant treatment. Ising et al [29] found that higher cortisol level after DEX administration prior to $\mathrm{CRH}$ stimulation was associated with a favorable treatment outcome. Two recent studies showed that response to antidepressant treatment was more favorable in depressive patients whose peak cortisol levels during the DEX/CRH test were reduced after the initiation of the treatment $[30,31]$. Further, in the study by Binder et al [32], antidepressant response was associated with higher cortisol response to the DEX/CRH test in male, but not female, patients. It is plausible that the DEX/CRH test and the antidepressant response are related, since antidepressants may exert their clinical effects, at least in part, by reducing the activity of the HPA system $[33,34]$. The fact that both the HPA axis activity and the $I L-1 \beta$ gene polymorphism influence the response to antidepressants further supports the evidence of reciprocal relationships between the HPA system and IL- $1 \beta$.

These previous findings prompted us to examine the possible association of polymorphisms in the $I L-1 \beta$ and the HPA function. In the present study, the relationship between the $I L-1 \beta$ gene polymorphisms and the results of the DEX/CRH test was examined in healthy subjects.
Because gender effects on measures of HPA axis function have been previously reported [32,35], a two-way factorial analysis of variance (ANOVA) was performed with the DEX/CRH test results as the dependent variable and genotype and gender as independent variables to determine the possible interaction effects between the polymorphisms and gender.

\section{Methods}

\section{Subjects}

Subjects were 179 adult healthy volunteers (45 males: mean age $40.5 \pm 15.8$ years, 134 females: mean age 47.1 \pm 13.2 years) recruited from the community through advertisements in free local information magazines and by our website announcement. Most of the subjects were from our previous sample, in which the relationship between stress, sleep, and HPA function was examined [36-38]. All subjects were biologically unrelated Japanese individuals without current or past history of psychiatric treatment, and were screened with a direct contact interview by a research psychiatrist using the Japanese version of the Mini International Neuropsychiatric Interview (M.I.N.I.) $[39,40]$ to rule out any axis I psychiatric disorders. Participants were excluded if they had prior medical histories of central nervous system disease or severe head injury, if they met the criteria for substance abuse or dependence or mental retardation, if they had received glucocorticoid treatment, psychotropic treatment, antihypertensive medications, oral contraceptives, or estrogen replacement therapies in the previous month, or if they suffered from any inflammatory, infectious, or systemic immune diseases, based on self-reports, at the time of assessment. The study protocol was approved by the ethics committee at the National Center of Neurology and Psychiatry, Japan. After description of the study, written informed consent was obtained from every subject.

\section{Genotyping}

Five tagging single nucleotide polymorphisms (SNPs) in a region 1 kilobase $(\mathrm{kb})$ upstream to $1 \mathrm{~kb}$ downstream of the $I L-1 \beta$ gene (rs2853550, rs1143634, rs1143633, rs1143630, rs16944) were selected by Haploview 4.2 [41] using Japanese and Chinese population in the HapMap SNP set (release 22), at an $\mathrm{r}^{2}$ threshold of 0.80 with a minor allele frequency greater than 0.1. Genomic organization and linkage disequilibrium structure of the $I L-1 \beta$ gene are shown in Figure 1. Genomic DNA was prepared from the venous blood according to standard procedures. The SNPs were genotyped using the TaqMan 5'-exonuclease allelic discrimination assay. Thermal cycling conditions for polymerase chain reaction were 1 cycle at $95^{\circ} \mathrm{C}$ for 10 minutes followed by 50 cycles of $92^{\circ} \mathrm{C}$ for 15 seconds and $60^{\circ} \mathrm{C}$ for 1 minute. The 


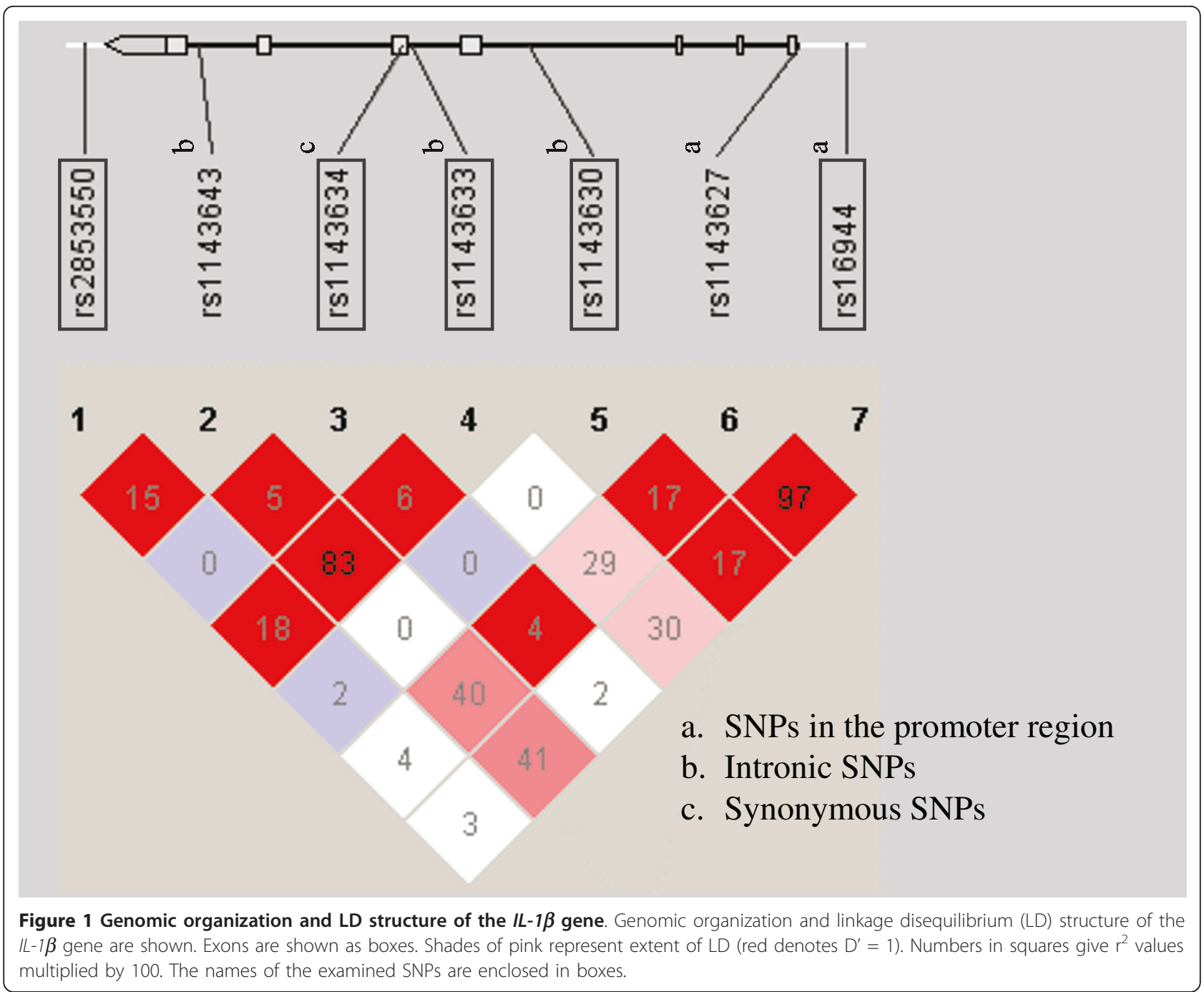

allele-specific fluorescence was measured with $\mathrm{ABI}$ PRISM 7900 Sequence Detection Systems (Applied Biosystems, Foster city, CA, USA). Genotype data were read blind to the DEX/CRH test results. Ambiguous genotype data were not included in the analysis.

\section{DEX/CRH test}

The DEX/CRH test was administered according to a protocol proposed in a previous report [18], which was also employed in our recent report [36]. The subjects were administered $1.5 \mathrm{mg}$ of DEX (Banyu Pharmaceutical Corporation, Tokyo, Japan) orally at $23.00 \mathrm{~h}$. On the next day, they attended our laboratory and sat on a comfortable couch in a calm room. A vein was cannulated at $14.30 \mathrm{~h}$ to collect blood samples at 15.00 and $16.00 \mathrm{~h}$ via an intravenous catheter. Human CRH $(100 \mu \mathrm{g})(\mathrm{hCRH}$ 'Mitsubishi', Mitsubishi Pharma Corporation, Tokyo, Japan) was administered intravenously at $15.00 \mathrm{~h}$, immediately after the first blood collection. Subjects fasted and rested semi-supine throughout the testing. Blood samples were immediately centrifuged and stored at $-20^{\circ} \mathrm{C}$. Plasma concentrations of cortisol were measured by radioimmunoassay at SRL Corporation (Tokyo, Japan). The detection limit for cortisol was $1.0 \mu \mathrm{g} / \mathrm{dl}$. Cortisol values under the detection limit were treated as $0 \mu \mathrm{g} / \mathrm{dl}$. The intra-assay coefficients of variation at $2.37 \mu \mathrm{g} / \mathrm{dl}$, $13.02 \mu \mathrm{g} / \mathrm{dl}$, and $36.73 \mu \mathrm{g} / \mathrm{dl}$ were $6.90 \%, 4.94 \%$, and $5.78 \%$, respectively. The inter-assay coefficients of variation at $2.55 \mu \mathrm{g} / \mathrm{dl}, 13.04 \mu \mathrm{g} / \mathrm{dl}$, and $34.17 \mu \mathrm{g} / \mathrm{dl}$ were $8.91 \%, 6.03 \%$, and $6.44 \%$, respectively (SRL Corporation, Tokyo, Japan). Outcome measures of this neuroendocrine test were the DST-Cortisol (i.e., the concentration of cortisol $[\mu \mathrm{g} / \mathrm{dl}]$ at $15.00 \mathrm{~h}$ ) and DEX/CRH-Cortisol (i.e., the concentration of cortisol at $16.00 \mathrm{~h}$ ).

\section{Statistical analysis}

Deviations of genotype distributions from Hardy-Weinberg equilibrium (HWE) were assessed using the $\chi^{2}$ test 
for goodness of fit. To determine the interaction effects between genotype and gender, two-way factorial analysis of variance (ANOVA) was performed with the transformed cortisol levels as the dependent variable and genotype and gender as independent variables. Because the cortisol levels were not normally distributed, the aligned rank transformation method was used to transform the data prior to conducting ANOVA [42]. To correct for the multiple comparisons, statistical significance was set at two-tailed $P<0.01$ when the analysis was performed for each of the 5 SNPs. Otherwise, statistical significance was set at two-tailed $P<0.05$. Analyses were performed using the Statistical Package for the Social Sciences (SPSS) version 11.0 (SPSS Japan, Tokyo).

\section{Results}

None of the examined SNPs deviated significantly from HWE after Bonferroni correction (all $P>0.01$ ), although rs1143633 showed a trend towards excess of heterozygotes over Hardy-Weinberg expectations $\left(\chi^{2}=\right.$ $6.48, P<0.05)$. Age showed no significant correlation with DST-Cortisol or DEX/CRH-Cortisol in either gender (all $P>0.05$ ).

Additional file 1 (Table S1) presents the results of the two-way ANOVA performed with the transformed plasma cortisol levels as the dependent variable and genotype and gender as independent variables. Significant effects of genotype on DST-Cortisol were observed for rs1143633 and rs16944, with no significant gender effect or genotype $\times$ gender interaction. The means of the DST-Cortisol in each genotype of rs1143633 and rs16944 and the significance levels of Tukey's post hoc tests are shown in Figure 2. Regarding DEX/CRH-Cortisol, significant gender effects were demonstrated in three of the two-way ANOVA results. No significant genotype effect or genotype $\times$ gender interaction was observed for DEX/CRH-Cortisol.

\section{Discussion}

To our knowledge, this is the first study that revealed the possible role of $I L-1 \beta$ polymorphisms on HPA axis function. Two studies have reported the influence of

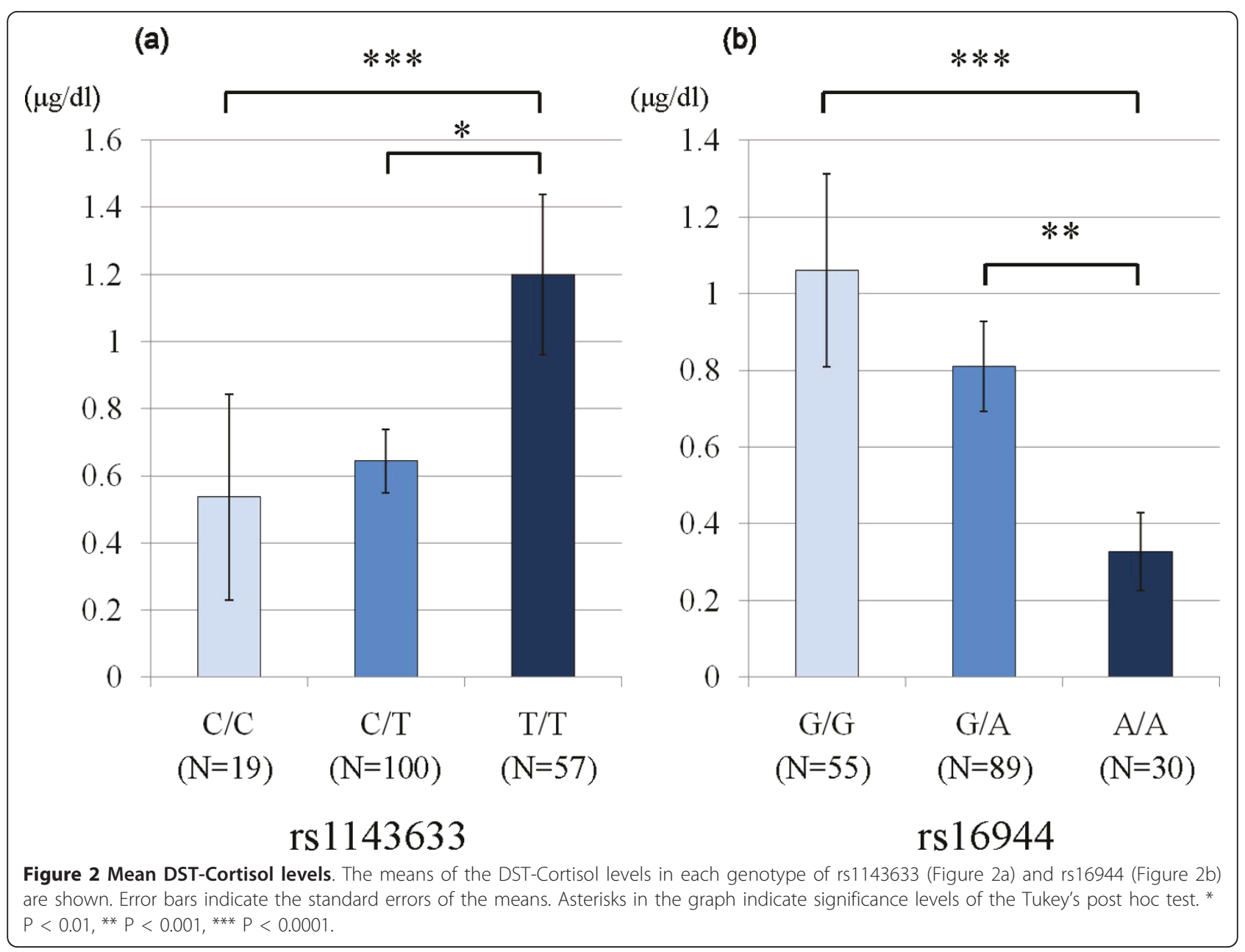


genetic polymorphisms on DEX suppression test (DST) $[43,44]$, one of which has shown that an allele in a polymorphism within the $C R H B P$ gene, which regulates the CRH system, was associated with pronounced DEX suppression of corticotropin and with nonresponse to citalopram treatment in depressed subjects [43]. Some studies have also reported the influence of genetic polymorphisms on DEX/CRH-Cortisol. Schule et al [45] reported that brain-derived neurotrophic factor Val66Met polymorphism is associated with HPA axis activity during the DEX/CRH test in depressed patients. There is also a study reporting an association of a polymorphism of the preprogalanin gene with DEX/CRH test results and antidepressant treatment response [46]. Our study adds to accumulating evidence that genetic factors could influence the activity of the HPA axis.

Previous studies have shown associations of HPA axis activity assessed by the DEX/CRH test with antidepressant treatment [30-32]. Furthermore, higher cortisol level after DEX administration prior to $\mathrm{CRH}$ stimulation was also associated with a favorable treatment outcome [29]. Since the $I L-1 \beta$ gene polymorphism is also known to influence the response to antidepressants, we expected that association between $I L-1 \beta$ gene and HPA activity assessed by the DEX/ $\mathrm{CRH}$ test would be found. However, our results showed that only DST-Cortisol, but not DEX/CRHCortisol, was significantly associated with the $I L-1 \beta$ gene polymorphisms. Thus, the relationship of the HPA activity and the $I L-1 \beta$ gene polymorphism with the antidepressant response could not be fully explained from our findings. Although the present study was performed in healthy subjects, it is possible that a different regulatory mechanism of HPA axis which overweighs the effect of the polymorphisms examined in the present study may exist in depressive patients. Further studies must be carried out to determine HPA axis regulation in patients with depression.

Significant gender effects were observed for DEX/ CRH-Cortisol, consistent with previous studies $[18,47]$. However, as mentioned above, the DEX/CRH-Cortisol did not show significant associations with any of the SNPs examined. This may partly be explained by the putative action of IL- $1 \beta$ on hypothalamus. Animal studies have shown that IL-1 $\beta$ is involved in the noradrenaline-induced release of $\mathrm{CRH}$ from the hypothalamus $[28,48]$. Therefore, higher IL- $1 \beta$ expression in the brain may facilitate the release of CRH even when the suppressive effect of DEX is exerted, resulting in higher DST-Cortisol. On the other hand, the effect of IL- $1 \beta$ on the DEX/CRH-Cortisol could be small if the administration of CRH overweighs the effect of IL- $1 \beta$ expression level. Because rs1143634 and rs1143633 showed a trend towards association with DEX/CRH-Cortisol $(P<0.1)$, a further study with a larger sample size may be warranted.

The findings on biological roles of rs 16944 polymorphism have not been consistent across studies. A/A genotype has been associated with higher gastric mucosa IL-1 $\beta$ levels in $H$. pylori positive population [49]. On the other hand, mononuclear cells from subjects with G/G genotype showed an increased release of IL-1 $\beta$ after stimulation with lipopolysaccharide [50]. Recent studies suggest that the functional role of rs16944 may depend on the $I L-1 \beta$ promoter region haplotypes including rs16944 and rs1143627 [51-54]. Although the findings are inconsistent, these previous studies suggest that rs16944 could affect the expression levels of IL-1 $\beta$. The biological role of rs1143633, on the other hand, has not been previously reported.

Previous studies showed that administration of DEX inhibited lipopolysaccharide (LPS)-stiumulated production of IL-1 $\beta[55,56]$, suggesting that DEX may affect the function of $I L-1 \beta$ gene. Therefore, future studies should examine the influence of $I L-1 \beta$ gene polymorphisms on not only basal IL- $1 \beta$ levels but also DEXinduced IL-1 $\beta$ levels. The decrease of the LPS-induced $I L-1 \beta$ gene expression by DEX may be caused by the inhibition of nuclear factor binding to the $I L-1 \beta$ gene promoter [56]. It is noteworthy that, in the present study, the HPA response to DEX was affected by rs 16944 , which is located in the promoter region of the IL-1 $\beta$ gene.

The following limitations must be considered when interpreting the results. First, since the DEX/CRH test used here was based on a simple test protocol, we could not calculate the cortisol area under the curve $[57,58]$. We also did not measure the adrenocorticotropic hormone levels, which was measured in previous studies to determine the pituitary glucocorticoid negative feedback [30,45,57-59]. Moreover, we did not measure the baseline levels of cortisol. The extent to which the cortisol was suppressed in response to DEX administration could not be determined from our data. There may have been a genotype dependent alteration of the baseline cortisol levels, which appeared in the present study as a genotype effect on DST-Cortisol. This will need further investigation. We also did not perform physical examination to rule out physical disorders. As the presence or absence of inflammatory and immune diseases were based only on self-reports, the results may have been affected by unrecognized inflammatory processes in some participants. Furthermore, the lack of data on menstrual cycle or menopausal status in the female participants may have also influenced the results. Another limitation of the study is that we did not assess the biological role of $I L-1 \beta$ polymorphisms. The association of IL- $1 \beta$ expression level with the $I L-1 \beta$ polymorphisms 
needs to be investigated in the future. Finally, the present study included only healthy subjects. Whether the relationship between $I L-1 \beta$ gene polymorphisms and the HPA function is altered in depressed patients remain to be elucidated.

\section{Conclusions}

The present study revealed that the cortisol response to administration of DEX is influenced by the $I L-1 \beta$ gene polymorphisms. The $\mathrm{G}$ allele of rs16944 and the $\mathrm{T}$ allele of rs1143633 were significantly associated with higher DST-Cortisol. On the other hand, no significant associations of the $I L-1 \beta$ gene polymorphisms with the DEX/ $\mathrm{CRH}$-Cortisol were observed. Our study adds to accumulating evidence that IL-1 $\beta$ is involved in the regulation of the HPA axis. Confirmation of our findings in futures studies may add new insight into the communication between the immune system and the HPA axis.

\section{Additional material}

Additional file 1: Table S1. The results of the two-way ANOVA ANOVA was performed with the transformed cortisol levels as the dependent variable and genotype and gender as independent variables. $P$ values $<0.01$ are shown in bold

\section{Acknowledgements}

This study was supported by Health and Labor Sciences Research Grants (Comprehensive Research on Disability, Health, and Welfare), Grant-in-Aid for Scientific Research from the Japan Society for the Promotion of Science (JSPS), Core Research of Evolutional Science \& Technology (CREST), Japan Science and Technology Agency (JST), the Strategic Research Program for Brain Sciences by the Ministry of Education, Culture, Sports, Science and Technology of Japan (Understanding of molecular and environmental bases for brain health), and Intramural Research Grant for Neurological and Psychiatric Disorders of NCNP (HK.).

\section{Author details}

${ }^{1}$ Department of Mental Disorder Research, National Institute of Neuroscience, National Center of Neurology and Psychiatry, Kodaira, Tokyo, 187-8502, Japan. ${ }^{2}$ Department of Psychiatry, Shinshu University School of Medicine, Matsumoto, 390-8621, Japan. ${ }^{3}$ Department of Medical Genetics Majors of Medical Sciences, Graduate School of Comprehensive Human Sciences, University of Tsukuba, Tsukuba, 305-8577, Japan. ${ }^{4}$ Core Research of Evolutional Science \& Technology (CREST), Japan Science and Technology Agency (JST), Tokyo, 102-0075, Japan.

\section{Authors' contributions}

DS and HK designed the study and DS wrote the draft of the manuscript. $D S, H H, T T, K H, M O$, and $H K$ screened the study participants using the Mini International Neuropsychiatric Interview (M.I.N.I.). HH performed the DEX/CRH test. DS and $\mathrm{YI}$ performed the genotyping. DS, HH, and TF undertook the statistical analysis. HK supervised the data analysis and writing of the paper. $\mathrm{TH}$ and NA also supervised the writing of the paper and gave critical comments on the manuscript. All authors contributed to and have approved the final manuscript.

\section{Competing interests}

The authors declare that they have no competing interests.

Received: 24 March 2011 Accepted: 5 July 2011 Published: 5 July 2011
References

1. Owen BM, Eccleston D, Ferrier IN, Young AH: Raised levels of plasma interleukin-1beta in major and postviral depression. Acta Psychiatr Scand 2001, 103:226-228.

2. Thomas AJ, Davis S, Morris C, Jackson E, Harrison R, O'Brien JT: Increase in interleukin-1beta in late-life depression. Am J Psychiatry 2005, 162:175-177.

3. Piletz JE, Halaris A, lqbal O, Hoppensteadt D, Fareed J, Zhu H, Sinacore J, Devane CL: Pro-inflammatory biomakers in depression: treatment with venlafaxine. World J Biol Psychiatry 2009, 10:313-323.

4. Anisman H, Ravindran AV, Griffiths J, Merali Z: Endocrine and cytokine correlates of major depression and dysthymia with typical or atypical features. Mol Psychiatry 1999, 4:182-188.

5. Brambilla F, Monteleone P, Maj M: Interleukin-1beta and tumor necrosis factor-alpha in children with major depressive disorder or dysthymia. $J$ Affect Disord 2004, 78:273-277.

6. Castanon N, Bluthe RM, Dantzer R: Chronic treatment with the atypical antidepressant tianeptine attenuates sickness behavior induced by peripheral but not central lipopolysaccharide and interleukin-1 beta in the rat. Psychopharmacology (Berl) 2001, 154:50-60.

7. Merali Z, Brennan K, Brau P, Anisman H: Dissociating anorexia and anhedonia elicited by interleukin-1beta: antidepressant and gender effects on responding for "free chow" and "earned" sucrose intake. Psychopharmacology (Berl) 2003, 165:413-418.

8. Koo JW, Duman RS: Evidence for IL-1 receptor blockade as a therapeutic strategy for the treatment of depression. Curr Opin Investig Drugs 2009, 10:664-671.

9. Norman GJ, Karelina K, Zhang N, Walton JC, Morris JS, Devries AC: Stress and IL-1beta contribute to the development of depressive-like behavior following peripheral nerve injury. Mol Psychiatry 2010, 15:404-414.

10. Yu YW, Chen TJ, Hong CJ, Chen HM, Tsai SJ: Association study of the interleukin-1 beta (C-511T) genetic polymorphism with major depressive disorder, associated symptomatology, and antidepressant response. Neuropsychopharmacology 2003, 28:1182-1185.

11. Misener VL, Gomez L, Wigg KG, King N, Kiss E, Daroczi G, Kapornai K, Tamas Z, Mayer L, Gadoros J, et al: Tagging SNP association study of the IL-1beta gene (IL1B) and childhood-onset mood disorders. Am J Med Genet B Neuropsychiatr Genet 2009, 150B:653-659.

12. Misener VL, Gomez L, Wigg KG, Luca P, King N, Kiss E, Daroczi G, Kapornai K, Tamas Z, Mayer L, et al: Cytokine Genes TNF, IL1A, IL1B, IL6, IL1RN and IL10, and childhood-onset mood disorders. Neuropsychobiology 2008, 58:71-80.

13. Tadic A, Rujescu D, Muller MJ, Kohnen R, Stassen HH, Szegedi A, Dahmen N: Association analysis between variants of the interleukin1 beta and the interleukin-1 receptor antagonist gene and antidepressant treatment response in major depression. Neuropsychiatr Dis Treat 2008, 4:269-276.

14. Baune BT, Dannlowski U, Domschke K, Janssen DG, Jordan MA, Ohrmann P, Bauer J, Biros E, Arolt V, Kugel H, et al: The interleukin 1 beta (IL1B) gene is associated with failure to achieve remission and impaired emotion processing in major depression. Biol Psychiatry 2010, 67:543-549.

15. Holsboer F, Ising M: Stress hormone regulation: biological role and translation into therapy. Annu Rev Psychol 2010, 61:81-109, C101-111.

16. de Kloet ER, Joels $M$, Holsboer F: Stress and the brain: from adaptation to disease. Nat Rev Neurosci 2005, 6:463-475.

17. Kunugi H, Urushibara T, Nanko S: Combined DEX/CRH test among Japanese patients with major depression. J Psychiatr Res 2004, 38:123-128.

18. Kunugi $H$, Ida I, Owashi T, Kimura M, Inoue $Y$, Nakagawa S, Yabana T, Urushibara T, Kanai R, Aihara M, et al: Assessment of the dexamethasone/ $\mathrm{CRH}$ test as a state-dependent marker for hypothalamic-pituitary-adrenal (HPA) axis abnormalities in major depressive episode: a Multicenter Study. Neuropsychopharmacology 2006, 31:212-220.

19. Raison $\mathrm{CL}$, Borisov AS, Woolwine BJ, Massung B, Vogt G, Miller AH: Interferon-alpha effects on diurnal hypothalamic-pituitary-adrenal axis activity: relationship with proinflammatory cytokines and behavior. $\mathrm{Mo}$ Psychiatry 2010, 15:535-547.

20. Bauer ME, Papadopoulos A, Poon L, Perks P, Lightman SL, Checkley S, Shanks N: Altered glucocorticoid immunoregulation in treatment resistant depression. Psychoneuroendocrinology 2003, 28:49-65.

21. Schuld A, Schmid DA, Haack M, Holsboer F, Friess E, Pollmacher T: Hypothalamo-pituitary-adrenal function in patients with depressive 
disorders is correlated with baseline cytokine levels, but not with cytokine responses to hydrocortisone. J Psychiatr Res 2003, 37:463-470

22. Weinstein AA, Deuster PA, Francis JL, Bonsall RW, Tracy RP, Kop WJ: Neurohormonal and inflammatory hyper-responsiveness to acute mental stress in depression. Biol Psychol 2010, 84:228-234.

23. Schiepers OJ, Wichers MC, Maes M: Cytokines and major depression. Prog Neuropsychopharmacol Biol Psychiatry 2005, 29:201-217.

24. Muller N, Schwarz MJ: The immune-mediated alteration of serotonin and glutamate: towards an integrated view of depression. Mol Psychiatry 2007, 12:988-1000

25. Maes M, Bosmans E, Meltzer HY, Scharpe S, Suy E: Interleukin-1 beta: a putative mediator of HPA axis hyperactivity in major depression? Am J Psychiatry 1993, 150:1189-1193.

26. Besedovsky H, del Rey A, Sorkin E, Dinarello CA: Immunoregulatory feedback between interleukin-1 and glucocorticoid hormones. Science 1986, 233:652-654

27. Berkenbosch F, van Oers J, del Rey A, Tilders F, Besedovsky H: Corticotropin-releasing factor-producing neurons in the rat activated by interleukin-1. Science 1987, 238:524-526.

28. Hsieh $\mathrm{CH}, \mathrm{Li} \mathrm{HY}$, Chen JC: Nitric oxide and interleukin-1 beta mediate noradrenergic induced corticotrophin-releasing hormone release in organotypic cultures of rat paraventricular nucleus. Neuroscience 2010, 165:1191-1202.

29. Ising M, Kunzel HE, Binder EB, Nickel T, Modell S, Holsboer F: The combined dexamethasone/CRH test as a potential surrogate marker in depression. Prog Neuropsychopharmacol Biol Psychiatry 2005, 29:1085-1093.

30. Ising M, Horstmann S, Kloiber S, Lucae S, Binder EB, Kern N, Kunzel HE, Pfennig A, Uhr M, Holsboer F: Combined dexamethasone/corticotropin releasing hormone test predicts treatment response in major depression - a potential biomarker? Biol Psychiatry 2007, 62:47-54.

31. Schule C, Baghai TC, Eser D, Hafner S, Born C, Herrmann S, Rupprecht R: The combined dexamethasone/CRH Test (DEX/CRH test) and prediction of acute treatment response in major depression. PLoS One 2009, 4: e4324.

32. Binder EB, Kunzel $H E$, Nickel $T$, Kern N, Pfennig A, Majer M, Uhr M, Ising M, Holsboer F: HPA-axis regulation at in-patient admission is associated with antidepressant therapy outcome in male but not in female depressed patients. Psychoneuroendocrinology 2009, 34:99-109.

33. Heuser IJ, Schweiger U, Gotthardt U, Schmider J, Lammers CH, Dettling M, Yassouridis A, Holsboer F: Pituitary-adrenal-system regulation and psychopathology during amitriptyline treatment in elderly depressed patients and normal comparison subjects. Am J Psychiatry 1996, 153:93-99.

34. Nickel T, Sonntag A, Schill J, Zobel AW, Ackl N, Brunnauer A, Murck H, Ising M, Yassouridis A, Steiger A, et al: Clinical and neurobiological effects of tianeptine and paroxetine in major depression. J Clin Psychopharmacol 2003, 23:155-168.

35. Uhart M, Chong RY, Oswald L, Lin PI, Wand GS: Gender differences in hypothalamic-pituitary-adrenal (HPA) axis reactivity. Psychoneuroendocrinology 2006, 31:642-652.

36. Hori H, Ozeki Y, Teraishi T, Matsuo J, Kawamoto Y, Kinoshita Y, Suto S, Terada S, Higuchi T, Kunugi H: Relationships between psychological distress, coping styles, and HPA axis reactivity in healthy adults. J Psychiatr Res 2010, 44:865-873.

37. Hori H, Teraishi T, Sasayama D, Ozeki Y, Matsuo J, Kawamoto Y, Kinoshita Y, Hattori K, Higuchi T, Kunugi H: Poor sleep is associated with exaggerated cortisol response to the combined dexamethasone/CRH test in a nonclinical population. J Psychiatr Res 2011.

38. Hori H, Teraishi T, Ozeki Y, Hattori K, Sasayama D, Matsuo J, Kawamoto $Y$, Kinoshita Y, Higuchi T, Kunugi H: Schizotypal personality in healthy adults is related to blunted cortisol responses to the combined dexamethasone/corticotropin-releasing hormone test. Neuropsychobiology 2011, 63:232-241.

39. Sheehan DV, Lecrubier $Y$, Sheehan $K H$, Amorim $P$, Janavs J, Weiller $E$, Hergueta T, Baker R, Dunbar GC: The Mini-International Neuropsychiatric Interview (M.I.N.I.): the development and validation of a structured diagnostic psychiatric interview for DSM-IV and ICD-10. J Clin Psychiatry 1998, 59(Suppl 20):22-33, quiz 34-57.

40. Otsubo T, Tanaka K, Koda R, Shinoda J, Sano N, Tanaka S, Aoyama H, Mimura M, Kamijima K: Reliability and validity of Japanese version of the Mini-International Neuropsychiatric Interview. Psychiatry Clin Neurosci 2005, 59:517-526.

41. Barrett JC, Fry B, Maller J, Daly MJ: Haploview: analysis and visualization of LD and haplotype maps. Bioinformatics 2005, 21:263-265.

42. Wobbrock JO, Findlater L, Gergle D, Higgins JJ: The Aligned Rank Transform for Nonparametric Factorial Analyses Using Only ANOVA Procedures. Proceedings of CHI 2011 Conference on Human Factors in Computing Systems 2011, 1:143-146.

43. Binder EB, Owens MJ, Liu W, Deveau TC, Rush AJ, Trivedi MH, Fava M, Bradley B, Ressler KJ, Nemeroff CB: Association of polymorphisms in genes regulating the corticotropin-releasing factor system with antidepressant treatment response. Arch Gen Psychiatry 2010, 67:369-379.

44. Kumsta R, Entringer S, Koper JW, van Rossum EF, Hellhammer DH, Wust S: Sex specific associations between common glucocorticoid receptor gene variants and hypothalamus-pituitary-adrenal axis responses to psychosocial stress. Biol Psychiatry 2007, 62:863-869.

45. Schule C, Zill P, Baghai TC, Eser D, Zwanzger P, Wenig N, Rupprecht R, Bondy B: Brain-derived neurotrophic factor Val66Met polymorphism and dexamethasone/CRH test results in depressed patients. Psychoneuroendocrinology 2006, 31:1019-1025.

46. Unschuld PG, lsing M, Roeske D, Erhardt A, Specht M, Kloiber S, Uhr M, Muller-Myhsok B, Holsboer F, Binder EB: Gender-specific association of galanin polymorphisms with HPA-axis dysregulation, symptom severity, and antidepressant treatment response. Neuropsychopharmacology 2010, 35:1583-1592.

47. Heuser IJ, Gotthardt U, Schweiger U, Schmider J, Lammers CH, Dettling M, Holsboer F: Age-associated changes of pituitary-adrenocortical hormone regulation in humans: importance of gender. Neurobiol Aging 1994, 15:227-231.

48. Schmidt ED, Aguilera G, Binnekade R, Tilders FJ: Single administration of interleukin-1 increased corticotropin releasing hormone and corticotropin releasing hormone-receptor mRNA in the hypothalamic paraventricular nucleus which paralleled long-lasting (weeks) sensitization to emotional stressors. Neuroscience 2003, 116:275-283.

49. Hwang IR, Kodama T, Kikuchi S, Sakai K, Peterson LE, Graham DY, Yamaoka Y: Effect of interleukin 1 polymorphisms on gastric mucosal interleukin 1 beta production in Helicobacter pylori infection. Gastroenterology 2002, 123:1793-1803.

50. lacoviello L, Di Castelnuovo A, Gattone M, Pezzini A, Assanelli D, Lorenzet R, Del Zotto E, Colombo M, Napoleone E, Amore C, et al: Polymorphisms of the interleukin-1beta gene affect the risk of myocardial infarction and ischemic stroke at young age and the response of mononuclear cells to stimulation in vitro. Arterioscler Thromb Vasc Biol 2005, 25:222-227.

51. Chen H, Wilkins LM, Aziz N, Cannings C, Wyllie DH, Bingle C, Rogus J, Beck JD, Offenbacher S, Cork MJ, et al: Single nucleotide polymorphisms in the human interleukin-1B gene affect transcription according to haplotype context. Hum Mol Genet 2006, 15:519-529.

52. Wen AQ, Wang J, Feng K, Zhu PF, Wang ZG, Jiang JX: Effects of haplotypes in the interleukin 1 beta promoter on lipopolysaccharideinduced interleukin 1 beta expression. Shock 2006, 26:25-30.

53. Wen $A Q$, Gu W, Wang J, Feng K, Qin L, Ying C, Zhu PF, Wang ZG, Jiang JX: Clinical relevance of interleukin-1 beta promoter polymorphisms (-1470, -511 and -31) in patients with major trauma. Shock 2010, 33(6):576-82.

54. Hall SK, Perregaux DG, Gabel CA, Woodworth T, Durham LK, Huizinga TW, Breedveld FC, Seymour AB: Correlation of polymorphic variation in the promoter region of the interleukin-1 beta gene with secretion of interleukin-1 beta protein. Arthritis Rheum 2004, 50:1976-1983.

55. Lekander M, Axen J, Knutsson U, Olgart Hoglund C, Werner S, Wikstrom AC, Stierna P: Cytokine inhibition after glucocorticoid exposure in healthy men with low versus high basal cortisol levels. Neuroimmunomodulation 2009, 16:245-250.

56. Jeon YJ, Han SH, Lee YW, Lee M, Yang KH, Kim HM: Dexamethasone inhibits IL-1 beta gene expression in LPS-stimulated RAW 264.7 cells by 
blocking NF-kappa B/Rel and AP-1 activation. Immunopharmacology 2000, 48:173-183.

57. Heuser I, Yassouridis A, Holsboer F: The combined dexamethasone/CRH test: a refined laboratory test for psychiatric disorders. $J$ Psychiatr Res 1994, 28:341-356.

58. Holsboer F: The corticosteroid receptor hypothesis of depression. Neuropsychopharmacology 2000, 23:477-501.

59. Schule C, Baghai T, Zwanzger P, Ella R, Eser D, Padberg F, Moller HJ, Rupprecht R: Attenuation of hypothalamic-pituitary-adrenocortical hyperactivity in depressed patients by mirtazapine. Psychopharmacology (Berl) 2003, 166:271-275.

doi:10.1186/1744-9081-7-23

Cite this article as: Sasayama et al:: Modulation of cortisol responses to the DEX/CRH test by polymorphisms of the interleukin-1beta gene in healthy adults. Behavioral and Brain Functions 2011 7:23.

\section{Submit your next manuscript to BioMed Central} and take full advantage of:

- Convenient online submission

- Thorough peer review

- No space constraints or color figure charges

- Immediate publication on acceptance

- Inclusion in PubMed, CAS, Scopus and Google Scholar

- Research which is freely available for redistribution

Submit your manuscript at www.biomedcentral.com/submit 